\title{
Effects of sequential nutritional support on nutritional status and expression of regulatory T lymphocyte in patients with early severe traumatic brain injury
}

This article was published in the following Dove Press journal:

Neuropsychiatric Disease and Treatment

\author{
Kai Jia' \\ Xin Tong' \\ Fang Liang ${ }^{2}$ \\ 'Department of Nutrition, Beijing \\ Chao-Yang Hospital, Capital \\ Medical University, Beijing 100020, \\ China; ${ }^{2}$ Department of Hyperbaric \\ Oxygen, Beijing Chao-Yang Hospital, \\ Capital Medical University, Beijing \\ 100020, China
}

\begin{abstract}
Objective: To investigate the effects of sequential nutritional support on nutritional status and immune regulation in patients with early severe traumatic brain injury (STBI).

Patients and methods: A total of 62 patients diagnosed with STBI enrolled from Chaoyang Hospital (Beijing, China) from February 2015 to October 2016 were divided into two groups. The observational group $(n=34)$ was given sequential nutritional support and the control group $(n=28)$ was given the standard formula of whole protein enteral preparations. The energy supply for the two groups was $30 \mathrm{kcal} / \mathrm{kg} / \mathrm{d}$ and protein $1.6 \mathrm{~g} / \mathrm{kg} / \mathrm{d}$, respectively. The albumin (ALB), total protein (TP), high-sensitivity C-reactive protein (Hs-CRP), neuron-specific enolase (NSE), Glasgow Coma Score (GCS), and regulatory T cells before and after nutritional treatment were measured in both groups.

Results: At the 14th day, the levels of ALB $(41.7 \pm 4.2 \mathrm{~g} / \mathrm{L})$ and TP $(70.6 \pm 4.9 \mathrm{~g} / \mathrm{L})$ were significantly higher than those in the control group $(33.5 \pm 2.3 \mathrm{~g} / \mathrm{L}$ and $62.3 \pm 3.9 \mathrm{~g} / \mathrm{L})(P<0.05)$. The levels of Hs-CRP and NSE were significantly lower in the observational group $(0.96 \pm 0.82 \mathrm{mg} / \mathrm{L}$ and $11.96 \pm 7.82 \mathrm{ng} / \mathrm{L})$ than in the control group $(1.17 \pm 0.74 \mathrm{mg} / \mathrm{L}$ and $19.17 \pm 6.74 \mathrm{ng} / \mathrm{L})(P<0.05)$. The GCS score in the observational group (11.5 \pm 2.9$)$ was significantly higher than that in the control group $(8.1 \pm 1.7)(P<0.05)$. The percentage of Tregs in the peripheral CD4 ${ }^{+}$lymphocytes was significantly lower in the observational group than in the control group $(P<0.05)$.

Conclusion: The effect of sequential nutritional support is better than conventional nutritional support in patients with STBI. The findings call for early identification of malnutrition and individual nutritional support.
\end{abstract}

Keywords: severe traumatic brain injury, enteral nutrition, sequential nutrition, regulatory T lymphocytes

\section{Introduction}

Early enteral nutrition (EN) in patients with severe traumatic brain injury (STBI) is superior to parenteral nutrition (PN). ${ }^{1}$ Since many patients are in a state of coma after STBI, the rate of basal metabolism will increase due to high stress. A previous study suggested that the mean amount of energy consumption in STBI patients was significantly higher than that of basic energy consumption at rest. ${ }^{2}$ Insufficient energy supply to STBI patients would lead to severe nutritional deficiency, immune dysfunction, interfering repair and functional compensation of the central nervous system, which further increased the risk of malnutrition and directly influenced the prognosis of patients. ${ }^{3}$ Zhang and $\mathrm{Jiang}^{4}$ reported that the incidence of nutritional
Correspondence: Kai Jia

Department of Nutrition, Beijing

Chao-Yang Hospital, Capital Medical

University, 8 South Gongti Road,

Chaoyang District, Beijing 100020, China

Tel +86 I35 20952187

Email ndazhj@I63.com
Neuropsychiatric Disease and Treatment 2018:14 |56|-1567

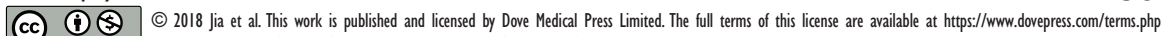

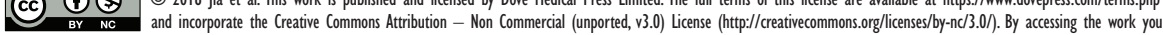
hereby accept the Terms. Non-commercial uses of the work are permitted without any further permission from Dove Medical Press Limited, provided the work is properly attributed. For permision for commercial use of this work, please see paragraphs 4.2 and 5 of our Terms (https://www.dovepress. com/terms.php). 
disorders could increase to $30 \%$ within 1 week after brain injury. Moreover, the delayed nutritional support would lead to rapid malnutrition and poor functional recovery in patients with STBI.

Currently, there is a consensus that early application of EN support is beneficial to patients with STBI. EN not only can provide sufficient nutritional substrate but also can activate the intestinal nerve-endocrine-immune network which can promote the secretion of intestinal hormones and facilitate gastrointestinal peristalsis. ${ }^{1,5}$ However, the appropriate method of EN support is still unclear. In addition, gastrointestinal dysfunction is prone to occur at $1-2$ weeks after brain injury, which makes it difficult for patients to achieve the target feeding amount (eg, $25 \mathrm{kcal} / \mathrm{kg} / \mathrm{d}$ ). In addition, reflux and vomiting caused by slow gastric motility and intracranial hypertension will increase the risk of malnutrition. Therefore, we proposed that sequential nutritional support for patients with STBI could ameliorate nutritional status and improve immune function. Regulatory T cells (Tregs) play an essential role in the immune system, including maintaining tolerance to self-antigens, preventing autoimmune disease, and negatively modulating the induction and proliferation of effector T cells. ${ }^{6-9}$ Liesz et al ${ }^{10}$ suggested that Treg cells were major cerebroprotective modulators of postischemic inflammatory brain damage targeting multiple inflammatory pathways. Treg cells and other effector $\mathrm{T}$ cells had been proven to express the biomarkers CD4, CD25, and Foxp3. ${ }^{11}$ Recently, studies proposed that low expression of CD127 coexpressed with Foxp3 and CD25, particularly in humans, could be used to distinguish Tregs from activated CD4 ${ }^{+} \mathrm{T}$ cells. ${ }^{12}$ In this study, $\mathrm{CD} 4^{+} \mathrm{CD} 25^{+} \mathrm{CD} 127 \mathrm{dim}$ cells were considered as activated Tregs. Therefore, we performed a comparative study about sequential nutritional support and traditional nutritional support for patients with STBI. The albumin (ALB), total protein (TP), high-sensitivity C-reactive protein (Hs-CRP), neuron-specific enolase (NSE), Glasgow Coma Score (GCS), and the percentage of $\mathrm{CD} 4{ }^{+} \mathrm{CD} 25^{+}$ $\mathrm{T}$ cells in the peripheral lymphocytes and the percentage of $\mathrm{CD}^{+} \mathrm{CD} 25^{+} \mathrm{CD} 127 \mathrm{dim} \mathrm{T}$ cells in the CD4 ${ }^{+}$lymphocytes were measured before and after nutritional support in both groups. More detailed information about nutritional status improvement and immune function recovery will be provided in this study.

\section{Patients and methods Patients}

The study sample included 62 STBI patients recruited at the Department of Neurosurgery and Hyperbaric Oxygen of Chaoyang Hospital (Beijing, China) from February 2015 to October 2016. The study sample consisted of 39 (62.9\%) males and $23(37.1 \%)$ females with mean age of 44.5 years (range from 21 to 68 years). The mean body weight was $65.7 \pm 18.9 \mathrm{~kg}$ and mean BMI was $20.1 \pm 3.5 \mathrm{~kg} / \mathrm{m}^{2}$. The daily intake of energy per person was calculated from height, weight, and nutritional status.

Inclusion criteria: 1) patients who were admitted to the hospital within $24 \mathrm{~h}$ after the onset of disease and who were diagnosed with brain contusion of closed or open brain injury based on history of the disease, signs and head CT scan (GCS for these patients ranged from 4 to 8 with a duration $>24 \mathrm{~h}$ ); 2) stable vital signs; 3) Nutritional Risk Screening 2002 (NRS2002) score $>3$, as recommended by the European Society for Parenteral and Enteral Nutrition (ESPEN) and accredited by the Chinese Society for Parenteral and Enteral Nutrition (CSPEN); and 4) survival more than 14 days.

Exclusion criteria: patients with organic disease, such as liver and kidney disease, gastrointestinal bleeding, malignancy, diabetes, and other endocrine diseases that affect protein metabolism.

This study was approved by the Beijing Chaoyang Hospital Ethics Committee of Capital University of Medical Sciences (2016-Section-83). Written informed consent was obtained from the patients' immediate family members before enrollment. Patients were divided into a control group (28 cases) and an observational group (34 cases) using a randomized table method. Nutritional screening, evaluation and treatment were performed for different nutritional support.

\section{Methods}

\section{Routine treatment}

Routine treatment for all patients are as follows: nerve nutrition, dehydration to decrease the intracranial pressure, maintenance of hemostasis, administration of hormones, prevention of infection, and maintenance of water, electrolyte, and acid-base balance. Intracranial hematoma removal and decompressed surgery were performed as per patients' conditions.

\section{Nutrition support}

After admission all patients were intubated with nasogastric or nasojejunal tube (diameter $2.7 \mathrm{ram}$, length $125 \mathrm{ram}$, with inductive wire and lubricated coating, produced by Fresenius Medical Company, Bad Homburg vor der Höhe, Germany). After intestinal function recovery, all patients were fed with EN via nasogastric or nasojejunal tube. The target energy supply was $30 \mathrm{kcal} / \mathrm{kg} / \mathrm{d}$ at the initial speed of $60 \mathrm{~mL} / \mathrm{h}$, and 
was gradually increased to either $80 \mathrm{~mL} / \mathrm{h}$ or $100 \mathrm{~mL} / \mathrm{h}$. In addition, the amount of intestinal nutrition and the drip speed were adjusted as per the patient's tolerance.

Observational group: Patients were given pepsin short peptide type EN (standard energy density, $125 \mathrm{~g} / \mathrm{kit}, 500 \mathrm{kcal}$, produced by Nutricia, Utrecht, the Netherlands) within $24 \mathrm{~h}$ of onset. Based on a patient's energy needs and tolerance, $500 \mathrm{kcal} / 500 \mathrm{~mL}, 750 \mathrm{kcal} / 750 \mathrm{~mL}$, or 1,000 kcal/1,000 mL nutrient solution was administered in the first 3 days of treatment. In brief, on the first day, pepsin $500 \mathrm{kcal} / 500 \mathrm{~mL}$ nutrient solution (protein $20 \mathrm{~g}$, fat $8.5 \mathrm{~g}$, carbohydrate $88 \mathrm{~g}$ ) was given to patients at a speed of $60 \mathrm{~mL} / \mathrm{h}$ continuous pumping. On the second day, pepsin $750 \mathrm{kcal} / 750 \mathrm{~mL}$ nutrient solution (protein $30 \mathrm{~g}$, fat $12.75 \mathrm{~g}$, carbohydrate $132 \mathrm{~g}$ ) was given at the rate of $80 \mathrm{~mL} / \mathrm{h}$ to enhance the patient's nutrition, whereas on the third day, 1,000 kcal/1,000 mL nutrient solution (protein $40 \mathrm{~g}$, fat $17 \mathrm{~g}$, carbohydrate $176 \mathrm{~g}$ ) was infused at the rate of $100 \mathrm{~mL} / \mathrm{h}$. The rest of the energy was provided by total parenteral nutrition (TPN; prepared with glucose, 20\% fat milk, 18 kinds of amino acids, water-soluble vitamins, fat-soluble vitamins, alanyl glutamine, electrolytes, and trace elements). After $48 \mathrm{~h}$, the total volume and drip rate were modified as guided by the patient's intestinal tolerance. Based on different energy requirements of each person, EN was gradually transferred to the short peptide and whole protein method after $72 \mathrm{~h}$. Further, the proportion of EN was also adjusted. During this period, whole protein powder (Guangzhou Bangshi Biotechnology Co., Ltd, Guangzhou, China; specifications: $300 \mathrm{~g} /$ tank, energy 5,040 kJ; $15 \mathrm{~g}$ protein powder containing $11.2 \mathrm{~g}$ protein) was added to meet the protein requirement of $1.6 \mathrm{~g} / \mathrm{kg} / \mathrm{d}$.

Control group: the control group were fed with Enteral Nutritional Suspension (Nutricia, specifications: $500 \mathrm{~mL} /$ bottle, energy 3,150 kJ, $750 \mathrm{kcal}$, protein $30 \mathrm{~g}$, fat $29.2 \mathrm{~g}$, carbohydrate $184 \mathrm{~g}$; meet daily energy $30 \mathrm{kcal} / \mathrm{kg} / \mathrm{d}$ ).

\section{Testing indexes}

Nutritional indexes

The patient's ALB and TP were measured on the 1st day, 7th day, and 14th day after admission.

\section{Inflammatory damage indexes}

The patient's Hs-CRP and NSE were monitored on the 1 st day, 7 th day, and 14th day after admission.

\section{GCS}

The changes in GCS were measured in both groups on the 1 st day and 14 th day after admission.

\section{Immune indexes}

The percentage of $\mathrm{CD} 4^{+} \mathrm{CD} 25^{+} \mathrm{T}$ cells in the peripheral lymphocytes and the percentage of CD $4^{+} \mathrm{CD} 25^{+} \mathrm{CD} 127 \mathrm{dim}$ $\mathrm{T}$ cells in the $\mathrm{CD}^{+}$lymphocytes were used as an immune index. Briefly, the elbow vein blood was collected and all the specimens were measured within $2 \mathrm{~h}$. Ten $\mu \mathrm{L}$ CD25-CY and $10 \mu \mathrm{L}$ CD4-F1TC antibody were added to $100 \mu \mathrm{L}$ whole blood, and mixed and reacted with the primary antibodies in the dark for $15 \mathrm{~min}$. Additionally, $2 \mathrm{~mL}$ hemolytic agent was added and incubated for $10 \mathrm{~min}$ in a $37^{\circ} \mathrm{C}$ water bath. After the samples were completely hemolytic and washed with phosphate buffer (PBS), the cells were immediately detected by flow cytometry.

\section{Statistical analyses}

All statistical analyses were performed using SPSS 21.0 (IBM Corporation, Armonk, NY, USA). Continuous variables were summarized with mean \pm SD. The betweengroup comparison was done using either a parametric Student's $t$-test or a non-parametric rank sum test. A $P$-value $<0.05$ (two-tailed) was considered statistically significant.

\section{Results}

\section{Demographic characteristics}

A total of 62 adult patients (39 men and 23 women) with STBI were enrolled in this study and they were randomly divided into two groups, including an observational group $(n=34)$ and a control group $(n=28)$. As shown in Table 1 , the mean age of the observational group was $41.5 \pm 10.8$ years and the mean age of the control group was 45.4 \pm 9.6 years. There were no significant differences of mean age between two groups. The observational group consisted of $22(64.7 \%)$ males and $12(35.3 \%)$ females. There were $17(60.7 \%)$ men and $11(39.3 \%)$ women in the control group. There were no significant differences in GCS between the observational group $(5.5 \pm 1.3)$ and the control group (6.2 \pm 0.7$)$.

Table I Demographic characteristics

\begin{tabular}{lll}
\hline & $\begin{array}{l}\text { Observational } \\
\text { group }\end{array}$ & $\begin{array}{l}\text { Control } \\
\text { group }\end{array}$ \\
\hline $\begin{array}{l}\text { Number of patients } \\
\text { Age (years) }\end{array}$ & 34 & 28 \\
Sex & $41.5 \pm 10.8$ & $45.4 \pm 9.6$ \\
$\quad$ Male, $n$ & 22 & 17 \\
$\quad$ Female, $n$ & 12 & 11 \\
Glasgow Coma Score & $5.5 \pm 1.3$ & $6.2 \pm 0.7$ \\
\hline
\end{tabular}

Note: Data presented as mean \pm SD. 
Table 2 Changes in ALB and TP markers on the Ist, 7th, and I4th day after treatment in control and observational groups

\begin{tabular}{|c|c|c|c|c|c|c|c|}
\hline \multirow[t]{2}{*}{ Group } & \multirow[t]{2}{*}{$\mathbf{n}$} & \multicolumn{3}{|l|}{ ALB } & \multicolumn{3}{|l|}{ TP } \\
\hline & & Ist day & 7th day & I4th day & Ist day & 7th day & I4th day \\
\hline Control & 28 & $29.5 \pm 3.5$ & $27.9 \pm 3.2$ & $33.5 \pm 2.3$ & $63.9 \pm 2.8$ & $59.6 \pm 4.6$ & $62.3 \pm 3.9$ \\
\hline Observational & 34 & $27.7 \pm 3.0$ & $31.3 \pm 2.9$ & $41.7 \pm 4.2 *$ & $60.3 \pm 3.4$ & $62.2 \pm 4.9$ & $70.6 \pm 4.9 *$ \\
\hline
\end{tabular}

Notes: $* P<0.05$. Data presented as mean \pm SD.

Abbreviations: ALB, albumin; TP, total protein.

\section{Changes in nutritional indices before and after treatment in both groups}

The ALB and TP were slightly higher in the observational group than in the control group on the 7th day after treatment, but the difference between the two groups was non-significant $(P>0.05)$. On the 14th day, the two indices increased, and the difference between the groups was statistically significant $(P<0.05$, Table 2$)$.

\section{Changes of Hs-CRP and NSE before and after treatment in both groups}

Table 2 presents the changes of Hs-CRP and NSE on the 1st, 7 th, and 14th day after treatment. The observational group had significantly lower level of serum Hs-CRP than the control group from 7 th day $(P<0.05)$. The observational group had a non-significantly lower level of NSE indices than the control group on 7 th day, but a significantly lower level on 14 th day $(P<0.05$, Table 3$)$.

\section{Changes in GCS scores before and after treatment in both groups}

The GCS scores for the two groups before and after treatment are shown in Table 4. The observational group had a significantly higher GCS score than the control group on the 14th day $(P<0.05)$.

\section{Percentages of $\mathrm{CD} 4^{+} \mathrm{CD} 25^{+} \mathrm{T}$ cells and CD4 ${ }^{+}$CD25+CD 127dim T cells in the whole lymphocytes before and after treatment in both groups}

As shown in Table 5, in the control group there were no significant differences of the percentages of $\mathrm{CD} 4{ }^{+} \mathrm{CD} 25^{+}$
T cells/peripheral lymphocytes and $\mathrm{CD} 4{ }^{+} \mathrm{CD} 25^{+} \mathrm{CD} 127 \mathrm{dim}$ $\mathrm{T}$ cells/CD4 ${ }^{+}$lymphocytes in the whole lymphocytes at the $1 \mathrm{st}, 7 \mathrm{th}$, and 14th days. However, in the observational group, the percentage of $\mathrm{CD} 4^{+} \mathrm{CD} 25^{+} \mathrm{T}$ cells in the peripheral lymphocytes and the percentage of CD $4^{+} \mathrm{CD} 25^{+} \mathrm{CD} 127 \mathrm{dim}$ $\mathrm{T}$ cells in the $\mathrm{CD}^{+}$lymphocytes were significantly decreased at the 7 th and 14 th days.

\section{Discussion}

To the best of our knowledge, this study is the first to test the effect of sequential nutritional support on nutritional status and immune regulation in patients with early STBI. We found that the observational group who were given sequential nutritional support had higher levels of ALB and TP, and lower levels of serum Hs-CRP, NSE, and Treg cells compared with the control group who were given the standard formula of whole protein enteral preparations, suggesting a beneficial effect of sequential nutritional support. The findings provide important information on the treatment of early STBI and highlight the protection of the intestinal tract. However, these findings require validation in other studies.

In this study, we adopted short-peptide enteral nutritional transition and whole protein EN mixed feeding, and additionally added a high protein sequential treatment program for the observational group, with whole protein type EN for the control group. When patients in the control group were given the whole protein type EN preparations, a series of reactions occurred in their digestive tracts, often leading to intolerance, reflux, and diarrhea. They had lower levels of serum TP and ALB than the observational group on the 7th day after treatment, but their gastrointestinal motility function was normal, after checking the residual amount in their stomach. We suggested that even if the early EN was

Table 3 Changes of Hs-CRP and NSE before and after treatment in control and observational groups

\begin{tabular}{|c|c|c|c|c|c|c|c|}
\hline \multirow[t]{2}{*}{ Group } & \multirow[t]{2}{*}{$\mathbf{n}$} & \multicolumn{3}{|c|}{ Hs-CRP (mg/L) } & \multicolumn{3}{|c|}{ NSE (ng/L) } \\
\hline & & Ist day & 7th day & I4th day & Ist day & 7th day & I4th day \\
\hline Control & 28 & $2.62 \pm 0.85$ & $1.76 \pm 0.62$ & I. $.7 \pm 0.74$ & $27.32 \pm 8.85$ & $22.56 \pm 9.62$ & $19.17 \pm 6.74$ \\
\hline Observational & 34 & $2.5 \mathrm{I} \pm 0.74$ & I. $12 \pm 0.57 *$ & $0.96 \pm 0.82$ & $5.58 \pm 10.74$ & $19.72 \pm 11.57$ & II.96 $\pm 7.82 *$ \\
\hline$P$-value & & 0.261 & 0.015 & 0.047 & 0.087 & 0.061 & 0.012 \\
\hline
\end{tabular}

Note: $* P<0.05$.

Abbreviations: Hs-CRP, high-sensitivity C-reactive protein; NSE, neuron-specific enolase. 
Table 4 Changes in GCS before and after treatment in control and observational groups

\begin{tabular}{lllll}
\hline Group & $\mathbf{n}$ & I st day & 7th day & I 4th day \\
\hline Control & 28 & $6.3 \pm 1.5$ & $7.7 \pm 1.2$ & $8.1 \pm 1.7$ \\
Observational & 34 & $7.2 \pm 2.1$ & $9.4 \pm 2.6$ & $11.5 \pm 2.9 *$ \\
$P$-value & & 0.229 & 0.891 & 0.027 \\
\hline
\end{tabular}

Note: $* P<0.05$.

Abbreviation: GCS, Glasgow Coma Score.

administrated, this stage inhibits the gastrointestinal function. The digestion and decomposition of the whole protein increased the gastrointestinal burden and caused damage to intestinal mucosal cells, resulting in incomplete absorption of the whole type protein. We adopted the transition treatment program from short peptide to whole protein type gradually for the observational group. The observational group showed significantly higher levels of serum TP and ALB after high protein nutritional support, compared to the control group. It has been shown that $20 \%$ of the early nutrients of STBI patients was provided by the gastrointestinal tract, and this can then maintain the gastrointestinal mucosal structure. ${ }^{3}$ The small amount of short peptide at the early stage in the observational group is good for digestion, reduces the burden on the gastrointestinal tract, improves the patient's gastrointestinal tolerance, and thus stabilizes the physiological state after acute gastrointestinal injury in patients with STBI.

After traumatic brain injury, the local inflammatory response is activated and a large amount of inflammatory factors are released, leading to secondary injury. Meanwhile, the microglia activated in the central nervous system after the brain injury interact with Tregs through the media, and activate the Tregs. Tregs can aggravate the brain injury due to cerebral microcirculatory disturbance and thrombogenesis. ${ }^{13}$ Kleinschnitz et al ${ }^{14}$ suggested that Foxp $3^{+}$Tregs cells could induce microvascular dysfunction and ablation of Tregs reduced microvascular thrombus formation and improved cerebral reperfusion on stroke. Similarly, in this study, the percentage of Tregs in the whole lymphocytes significantly reduced after nutritional support. Tregs are a subset of $\mathrm{CD}^{+}$ $\mathrm{T}$ lymphocytes, accounting for about $5 \%-10 \%$ of all CD $4^{+}$ $\mathrm{T}$ lymphocytes. Activated Tregs can inhibit the activity of other T lymphocytes, leading to immunosuppression, which can reduce the immunity of patients in the acute phase of traumatic brain injury, thus leading to pulmonary infection and other complications. ${ }^{15}$ Sequential nutritional support could effectively protect the gastrointestinal function, reduce the release of intestinal bacteria or toxins, inhibit the displacement of inflammatory mediators, and prohibit the activation of Tregs, which could alleviate inflammatory responses and secondary injuries. ${ }^{16,17}$

Furthermore, this study selected Hs-CRP and NSE as indicators to assess the impact of sequential nutritional treatment on inflammatory damage of central nervous system in patients. CRP is a sensitive non-specific inflammatory marker, a type of acute protein produced when the body tissue is damaged or stimulated by inflammation. Hs-CRP is regarded as a marker of clinical infection and acute inflammatory response due to close relations to inflammation and the degree of tissue damage. ${ }^{18}$ Clinical trials suggested that CRP levels in patients with brain injury and cerebral hemorrhage are highly related to inflammation and prognosis. NSE is a type of nerve-specific protein which is highly sensitive and can reflect brain tissue injury, and has become an important index to judge brain injury and evaluate prognosis in recent years. ${ }^{19}$ In this study, Hs-CRP and NSE significantly decreased in both groups after treatment with EN, and the observational group had significantly lower levels of Hs-CRP at the 7th day compared with the control group, further demonstrating that sequential nutritional support could reduce the inflammatory damage of nerve cells through immunoregulation.

We used the neurological score to assess the prognosis and observed significantly higher GCS scores in the observational group than in the control group on the 14th day after treatment. Improvement of GCS scores indicated that sequential nutritional support could effectively and efficiently promote the cerebral functional recovery after STBI. Chiang et $\mathrm{al}^{20}$ demonstrated that $\mathrm{EN}$ within $48 \mathrm{~h}$ post-injury is associated with better survival, GCS recovery, and outcome among STBI patients, particularly in those with a GCS score of 6-8. Early EN should start within $48 \mathrm{~h}$ post-brain injury to reduce clinical malnutrition, prevent bacterial translocation from

Table 5 The percentage of $C D 4^{+} C D 25^{+} \mathrm{T}$ cells and $\mathrm{CD} 4^{+} \mathrm{CD} 25^{+} \mathrm{CD} 127 \mathrm{dim} \mathrm{T}$ cells in the whole lymphocytes in the control and observational groups before and after treatment

\begin{tabular}{|c|c|c|c|c|c|c|}
\hline \multirow[t]{2}{*}{ Group } & \multicolumn{3}{|c|}{$\mathrm{CD4}^{+} \mathrm{CD}^{2} 5^{+}$} & \multicolumn{3}{|c|}{$\mathrm{CD4}^{+} \mathrm{CD}^{2} 5^{+} \mathrm{CD} 127 \mathrm{dim}$} \\
\hline & Ist day & 7th day & I4th day & Ist day & 7th day & I4th day \\
\hline Control & $9.8 \pm 4.5$ & $5.9 \pm 2.2$ & $4.5 \pm 2.7$ & $20.7 \pm 5.4$ & $17.3 \pm 7.9$ & $16.7 \pm 4.2$ \\
\hline Observational & $10.9 \pm 6.8$ & $4.6 \pm 1.7^{*}$ & $2.3 \pm 1.9^{\#}$ & $19.3 \pm 6 . \mid$ & $11.2 \pm 4.8^{\#}$ & $9.6 \pm 4.9^{\#}$ \\
\hline
\end{tabular}

Notes: $* P<0.05 ;{ }^{*} P<0.01$. 
the gastrointestinal tract and improve outcome in patients with STBI.

Therefore, sequential nutritional support not only prevents reduction in the early protein level in patients with severe STBI, but also regulates immunity. Therefore, this regulation can meet the needs of abnormal metabolism, reduce nerve cell damage, and can promote the recovery of nerve function. Sequential EN support is advantageous in the formulation of the formula and adjustment of nutritional program over the conventional EN support. Sequential EN implementation depends largely on its ability to promote the repair of intestinal function, improve the patient's gastrointestinal tolerance, and reduce malnutrition, infection, and inflammatory damage caused by immunosuppression. The stability of the internal environment and effective nutritional support can greatly reduce the complications after STBI.

There were several limitations to this study, including an insufficient number of enrolled patients, lack of further comparison of different types of STBI, such as closed brain injury and open brain injury, surgical or non-surgical treatments of STBI, the lack of analysis of genetic and environmental effects, and the absence of follow-up research. Therefore, it is necessary to collect detailed information from more suitable patients in a future study.

\section{Conclusion}

Compared with conventional nutritional support, sequential nutritional support shows a better effect on nutritional status and immune regulation in patients with STBI. It could be widely applied to improve the quality of life of patients in clinical settings, although further validations are needed.

\section{Data sharing statement}

All necessary information about this study were presented in the manuscript. Raw data regarding our patients are not publicly available due to the respect and protection of our patients' privacy but are available from the corresponding authors upon reasonable request.

\section{Disclosure}

The authors report no conflicts of interest in this work.

\section{References}

1. Wang X, Dong Y, Han X, Qi XQ, Huang CG, Hou LJ. Nutritional support for patients sustaining traumatic brain injury: a systematic review and meta-analysis of prospective studies. PLoS One. 2013;8(3):e58838.
2. Perel P, Yanagawa T, Bunn F, Roberts I, Wentz R, Pierro A. Nutritional support for head-injured patients. Cochrane Database Syst Rev. 2006; (4):CD001530.

3. Chapple LA, Chapman MJ, Lange K, Deane AM, Heyland DK. Nutrition support practices in critically ill head-injured patients: a global perspective. Crit Care. 2016;20:6.

4. Zhang X, Jiang X. Effects of enteral nutrition on the barrier function of the intestinal mucosa and dopamine receptor expression in rats with traumatic brain injury. JPEN J Parenter Enteral Nutr. 2015;39(1): 114-123.

5. Friedel D, Modayil R, Stavropoulos SN. Per-oral endoscopic myotomy: major advance in achalasia treatment and in endoscopic surgery. World J Gastroenterol. 2014;20(47):17746-17755.

6. Baecher-Allan C, Brown JA, Freeman GJ, Hafler DA. CD4+CD25high regulatory cells in human peripheral blood. J Immunol. 2001;167(3): $1245-1253$.

7. Kiniwa Y, Miyahara Y, Wang HY, et al. CD8+ Foxp3+ regulatory $\mathrm{T}$ cells mediate immunosuppression in prostate cancer. Clin Cancer Res. 2007;13(23):6947-6958.

8. Yang Y, Paik JH, Cho D, Cho JA, Kim CW. Resveratrol induces the suppression of tumor-derived $\mathrm{CD} 4+\mathrm{CD} 25+$ regulatory $\mathrm{T}$ cells. Int Immunopharmacol. 2008;8(4):542-547.

9. Brait VH, Arumugam TV, Drummond GR, Sobey CG. Importance of $\mathrm{T}$ lymphocytes in brain injury, immunodeficiency, and recovery after cerebral ischemia. J Cereb Blood Flow Metab. 2012;32(4): 598-611.

10. Liesz A, Suri-Payer E, Veltkamp C, et al. Regulatory T cells are key cerebroprotective immunomodulators in acute experimental stroke. Nat Med. 2009;15(2):192-199.

11. Sakaguchi S, Vignali DA, Rudensky AY, Niec RE, Waldmann H. The plasticity and stability of regulatory T cells. Nat Rev Immunol. 2013; 13(6):461-467.

12. Liu W, Putnam AL, Xu-Yu Z, et al. CD127 expression inversely correlates with FoxP3 and suppressive function of human $\mathrm{CD} 4+\mathrm{T}$ reg cells. J Exp Med. 2006;203(7):1701-1711.

13. Möttönen M, Heikkinen J, Mustonen L, Isomäki P, Luukkainen R, Lassila O. CD4+ CD25+ T cells with the phenotypic and functional characteristics of regulatory $\mathrm{T}$ cells are enriched in the synovial fluid of patients with rheumatoid arthritis. Clin Exp Immunol. 2005;140(2): 360-367.

14. Kleinschnitz C, Kraft P, Dreykluft A, et al. Regulatory T cells are strong promoters of acute ischemic stroke in mice by inducing dysfunction of the cerebral microvasculature. Blood. 2013;121(4):679-691.

15. Pandey A, Shrivastava A, Solanki A. Study of atherogenic lipid profile, high sensitive C-reactive protein neurological deficit and short-term outcome in stroke subtypes. Iran J Neurol. 2016;15(3): $146-152$.

16. He F, Balling R. The role of regulatory $\mathrm{T}$ cells in neurodegenerative diseases. Wiley Interdiscip Rev Syst Biol Med. 2013;5(2):153-180.

17. Wang HY, Lee DA, Peng G, et al. Tumor-specific human CD4+ regulatory $\mathrm{T}$ cells and their ligands: implications for immunotherapy. Immunity. 2004;20(1):107-118.

18. Mousavi SN, Nematy M, Norouzy A, et al. Comparison of intensive insulin therapy versus conventional glucose control in traumatic brain injury patients on parenteral nutrition: a pilot randomized clinical trial. J Res Med Sci. 2014;19(5):420-425.

19. Lee JC, Park JH, Ahn JH, et al. New GABAergic neurogenesis in the hippocampal CA1 region of a gerbil model of long-term survival after transient cerebral ischemic injury. Brain Pathol. 2016;26(5): 581-592.

20. Chiang YH, Chao DP, Chu SF, et al. Early enteral nutrition and clinical outcomes of severe traumatic brain injury patients in acute stage: a multi-center cohort study. $J$ Neurotrauma. 2012;29(1):75-80. 
Neuropsychiatric Disease and Treatment

Dovepress

\section{Publish your work in this journal}

Neuropsychiatric Disease and Treatment is an international, peerreviewed journal of clinical therapeutics and pharmacology focusing on concise rapid reporting of clinical or pre-clinical studies on a range of neuropsychiatric and neurological disorders. This journal is indexed on PubMed Central, the 'PsycINFO' database and CAS,

and is the official journal of The International Neuropsychiatric Association (INA). The manuscript management system is completely online and includes a very quick and fair peer-review system, which is all easy to use. Visit http://www.dovepress.com/testimonials.php to read real quotes from published authors.

Submit your manuscript here: http://www.dovepress.com/neuropsychiatric-disease-and-treatment-journal 